\title{
Developing a Research Agenda for Nursing and Midwifery: A Modified Delphi Study
}

Monterosso, L., Ross-Adjie, G., \& Keeney, S. (2015). Developing a Research Agenda for Nursing and Midwifery: A Modified Delphi Study. Contemporary Nurse, Nov 13(epub), 1-27.

https://doi.org/10.1080/10376178.2015.1116372

Link to publication record in Ulster University Research Portal

\section{Published in:}

Contemporary Nurse

Publication Status:

Published online: 13/11/2015

DOI:

10.1080/10376178.2015.1116372

\section{Document Version}

Author Accepted version

\section{General rights}

Copyright for the publications made accessible via Ulster University's Research Portal is retained by the author(s) and / or other copyright owners and it is a condition of accessing these publications that users recognise and abide by the legal requirements associated with these rights.

\section{Take down policy}

The Research Portal is Ulster University's institutional repository that provides access to Ulster's research outputs. Every effort has been made to ensure that content in the Research Portal does not infringe any person's rights, or applicable UK laws. If you discover content in the Research Portal that you believe breaches copyright or violates any law, please contact pure-support@ulster.ac.uk. 
NURSE

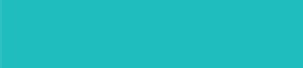

\section{Developing a Research Agenda for Nursing and Midwifery: A Modified Delphi Study}

\section{Leanne Monterosso, Gail Ross-Adjie \& Sinead Keeney}

To cite this article: Leanne Monterosso, Gail Ross-Adjie \& Sinead Keeney (2015): Developing a Research Agenda for Nursing and Midwifery: A Modified Delphi Study, Contemporary Nurse, DOI: $10.1080 / 10376178.2015 .1116372$

To link to this article: http://dx.doi.org/10.1080/10376178.2015.1116372

Accepted author version posted online: 13

Nov 2015.

Submit your article to this journal $[\pi$

Џll Article views: 4

Q View related articles $ᄃ$

View Crossmark data $₫$ 
NURSING AND MIDWIFERY RESEARCH AGENDA: A MODIFIED DELPHI STUDY

Publisher: Taylor \& Francis

Journal: Contemporary Nurse

DOI: $10.1080 / 10376178.2015 .1116372$

\section{DEVELOPING A RESEARCH AGENDA FOR NURSING AND MIDWIFERY: A MODIFIED DELPHI STUDY}

\section{Corresponding Author}

Leanne Monterosso

St John of God Murdoch Hospital

Centre for Nursing and Midwifery

100 Murdoch Drive

Murdoch WA 6150

Telephone: +61 893339765 leanne.monterosso@nd.edu.au

School of Nursing and Midwifery

University of Notre Dame Australia

School of Nursing and Midwifery

Edith Cowan University

\section{Co-authors}

Gail Ross-Adjie

Centre for Nursing and Midwifery

St John of God Murdoch Hospital

100 Murdoch Drive

Murdoch WA 6150

Telephone:+61893339737 gail.ross-adjie@sjog.org.au

School of Nursing and Midwifery

University of Notre Dame Australia

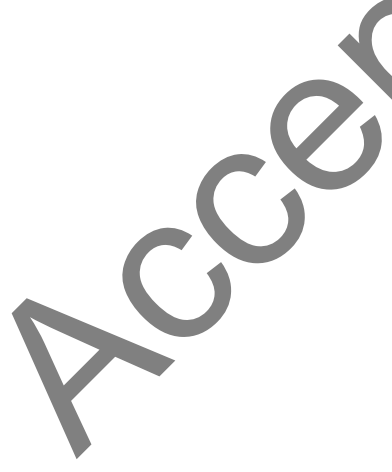

Sinead Keeney

School of Nursing

University of Ulster

Jordanstown Campus

Shore Road

Newtownabbey Co. Antrim

Telephone: +442890368463

sr.keeney@ulster.ac.uk

This work was supported by the University of Notre Dame Australia under the Research Incentive Scheme 
NURSING AND MIDWIFERY RESEARCH AGENDA: A MODIFIED DELPHI STUDY

\begin{abstract}
Aim We sought to ascertain the nursing and midwifery research priorities at a large private tertiary hospital in Australia.

Design A modified Delphi technique with two rounds of questionnaires.

Methods The first round survey was distributed to 448 nurses and midwives with a $19.2 \%$ $(n=86)$ response rate. Due to a low response rate in some specialties, the second round of the Delphi was only sent to nurses in the Learning and Organisational Development speciality who were asked to rank ten identified topics specific to learning and organisational development using a five point Likert-type scale.

Results Two hundred and fifty seven topics were identified in Round One and were condensed to 181 topics. Each topic was assigned to one of four categories: clinical audit; existing evidence base; research; or other topics which fell beyond the bounds of nursing or midwifery research. Twenty three research topics were identified with priorities focusing on learning and development and workforce issues.

Conclusion Priorities were congruent with the organisation's strategic workforce focus. Topics identified in this study will ensure that the nursing and midwifery research conducted at the study setting is relevant and reflects priorities as determined by clinical nurses and midwives.
\end{abstract}

Keywords: evidence-based practice; Delphi technique; midwifery; nursing; education 


\begin{tabular}{|c|c|}
\hline Reviewer 1 & \\
\hline Remove Western Australia from the title & $\begin{array}{l}\text { Title amended to "Developing a research } \\
\text { agenda for nursing and midwifery: A } \\
\text { modified Delphi study" } \\
\text { Header also modified to reflect this change. It } \\
\text { now reads "NURSING AND MIDWIFERY } \\
\text { RESEARCH AGENDA: A MODIFIED } \\
\text { DELPHI STUDY" }\end{array}$ \\
\hline $\begin{array}{l}\text { Can the authors please place the start of the } \\
\text { manuscript within the international context then } \\
\text { move into Australian context; Conclude with } \\
\text { international implications of this Aus data. Given } \\
\text { the International reach of the journal where } \\
\text { appropriate keep the focus on the international } \\
\text { context. }\end{array}$ & $\begin{array}{l}\text { The manuscript has been modified as } \\
\text { requested and text is highlighted in red on } \\
\text { pages } 3-4 \text {. The discussion has also been } \\
\text { amended to reflect the international } \\
\text { implications and how findings are consistent } \\
\text { with global nursing issues (e.g. workforce, } \\
\text { training and skill mix). }\end{array}$ \\
\hline Remove LOD and put in full & $\begin{array}{l}\text { All instances of the LOD abbreviations have } \\
\text { been removed and replaced with Learning } \\
\text { and organisational development. }\end{array}$ \\
\hline Reviewer 2 & \\
\hline $\begin{array}{l}\text { Thank you for considering the comments about } \\
\text { the use of the median instead of the mean. I } \\
\text { accept the authors' rationale for using the mean } \\
\text { that was explained in the 'Authors' response' } \\
\text { table. However, none of this explanation has been } \\
\text { included in the manuscript. Instead, the Keeney } \\
2010 \text { reference is still used, which, as I explained } \\
\text { in my last review of this manuscript, actually } \\
\text { calls for the median to be used. For this reason, it } \\
\text { is still my view that a more detailed explanation } \\
\text { justifying why using the mean to rank research } \\
\text { priorities was appropriate is needed in this paper. }\end{array}$ & $\begin{array}{l}\text { Thankyou. My omission - the manuscript } \\
\text { has been revised as per pages } 8-9 \text { "There is } \\
\text { variation in the statistics used to report } \\
\text { Delphi results (Keeney, Hasson \& McKenna, } \\
2011 \text { with some debate published in the } \\
\text { Delphi literature. While the median is } \\
\text { commonly used in Delphi research (Jacobs, } \\
\text { 1996; Avery et al., 2005; Vogel et al. 2009; } \\
\text { Becker et al., 2009), the mean is also } \\
\text { advocated by Delphi researchers (Murray \& } \\
\text { Jarman, 1987; Drennan et al., 2007; } \\
\text { Efstathiou et al., 2008; Ferguson et al. 2008). } \\
\text { As there is merit in viewing both the mean } \\
\text { and median, we have provided both in Table } \\
5 \text { for clarity. Research topics from the Round } \\
\text { Two questionnaire were therefore computed } \\
\text { according to means, standard deviations, } \\
\text { medians and IQR. As there is merit in } \\
\text { viewing both the mean and median, we have } \\
\text { provided both in Table } 5 \text { for clarity. Research } \\
\text { topics from the Round Two } \\
\text { questionnaire were therefore computed } \\
\text { according to means, standard deviations, } \\
\text { medians and IQR." }\end{array}$ \\
\hline $\begin{array}{l}\text { Also, the manuscript has not been amended } \\
\text { to include definitions for all levels of the } \\
\text { scale - it is only in the author's response table } \\
\text { (i.e. } 1=\text { unimportant; } 2=\text { of little importance; } \\
3=\text { moderately important; } 4=\text { important; } 5= \\
\text { very important). This is (? missing text) }\end{array}$ & $\begin{array}{l}\text { The previous version had been modified - } \\
\text { please see pages which have now been } \\
\text { highlighted in red on page } 8 \text { "In the scale, } 1= \\
\text { unimportant; } 2=\text { of little importance; } 3= \\
\text { moderately important; } 4=\text { important; } 5= \\
\text { very important.". }\end{array}$ \\
\hline
\end{tabular}


NURSING AND MIDWIFERY RESEARCH AGENDA: A MODIFIED DELPHI STUDY

\section{Main text}

Evidence based practice (EBP) has become the expected standard in health care delivery and is recognised as the framework to guide clinical decision making and the delivery of high quality care (Melnyk \& Fineout-Overholt, 2012). Evidence based practice is a judicious process that incorporates the best evidence from health research, clinical expertise, and patient preferences to guide health care decisions (Nursing and Midwifery Board of Australia, 2015). High-quality; empirically based; and clinically relevant research is considered to provide the best evidence and can determine the most clinicaland costeffective approaches to nursing care (Melnyk \& Fineout-Overholt, 2012). A fundamental step in the EBP process is to convert information needs from practice into focused, structured questions that can be studied empirically (Balakas \& Sparks, 2010; Melnyk \& FineoutOverholt, 2012). An understanding of the context in which care is provided is essential to ensure questions reflect specific patient and/or service focus (Balakas \& Sparks, 2010).

\section{Literature review}

Arguably the main use of the Delphi Technique in nursing research has been and continues to be the identification of research priorities (Wilkes, 2015). Over the last decade, nurse researchers have increasingly used the Delphi technique to identify research priorities within nursing and nidwifery (Wilson et al. 2012; Jordan et al., 2013; Green et al., 2014; Brenner et al., 2014; Wielenga et al., 2015). The identification of clinical priorities in nursing research can be traced back to the Oberst (1978) study. As well as the identification of clinical priorities, research priority setting is widely advocated to assist researchers and to ensure the alignment of funding with national evidence needs (Tong et al., 2015) whilst enhancing practice outcomes and policy (Sheikh et al., 2014). Studies using the Delphi Technique have set national and international research and 
NURSING AND MIDWIFERY RESEARCH AGENDA: A MODIFIED DELPHI STUDY

development priorities with the aim of influencing nursing policy (Ramelet \& Gill, 2012;

Tume et al., 2015). Other studies have been undertaken to establish research priorities for particular nursing organisations, for example, the European Federation of Critical Care Associations (Blackwood et al., 2011). In addition, the Delphi Technique has also been used to establish research priorities for specific conditions and diseases, for example, palliative care (de Vries et al., 2015), haemato-oncology nursing (Grundy et al., 2009) and mental health nursing (Wynaden et al., 2015).

Research priorities in healthcare are dynamic and constantly changing in response to developments in health systems; patient health outcomes; and priorities set by key advisory bodies concerned with the health and wellbeing of consumers. In Austrahia the current expectation is that nursing and midwifery research priorities should be aligned with national priorities for the health and wellbeing of the Australiancommunity (Australian College of Nursing, 2013; Department of Health Ageing, 2013). However, it is argued that research should also continue across the spectrum of healthcare where nurses and midwives practice. This study sought to identify and prioritise research topics as perceived by nurses and midwives in a large tertiary hospital in Australia to inform and advance evidence-based clinical practice, influence policy development and improve outcomes for patients, their families and clinicians. The study was aligned with the recently endorsed Centre for Nursing and Midwifery Research's commitment to actively engage nurses and midwives in the research process at all levels of the organisation. With the imminent launch of the Centre it was important to set a research agenda by exploring, documenting and comparing our research priorities with those reported internationally. 
NURSING AND MIDWIFERY RESEARCH AGENDA: A MODIFIED DELPHI STUDY

\begin{abstract}
Aim
The aim of this study was to identify the nursing and midwifery research priorities at a large private tertiary hospital in Western Australia.
\end{abstract}

\title{
Design
}

This study used a modified Delphi method to reach consensus on nursing and midwifery research topics. The Delphi technique is a systematic forecasting method involving interaction among a group of experts to reach consensus. It is a structured process, which uses a series of questionnaires (known as 'rounds') to gather information from a panel of 'informed individuals' (known as experts) in order to seek their judgment on a particular issue. Following Round One, responses from the expert panel are summarised and a new questionnaire (Round Two) is developed based on the results obtained from the first round of results. This second questionnaire is returned to each expert panel member and they are asked to provide a response. Repeat rounds of this process are carried out until consensus, or a point of diminishing returns, has been reached.

\section{Methods}

\section{Sample participants}

The study was undertaken in a large private tertiary hospital in metropolitan Perth, Western Australia. The hospital has 363 beds with a 20 bed hospice, a 24-hour emergency department, and a wide range of clinical and diagnostic services including medical, surgical, paediatric, maternity, intensive care and coronary care, orthopaedics, cancer and haematology. At the time of the study there were 448 full time equivalent nurses and midwives employed at the study hospital. The breakdown of nurses by classification was: senior registered nurses $(\mathrm{n}=22)$; clinical nurses/midwives $(\mathrm{n}=67)$; registered nurses/midwives $(\mathrm{n}=314)$; and enrolled 
NURSING AND MIDWIFERY RESEARCH AGENDA: A MODIFIED DELPHI STUDY

nurses $(n=45)$. All nurses and midwives were approached and 86 were recruited into the expert panel for the first Delphi round.

\section{Data collection}

Prior to the implementation of the study, particular attention was given to instructing nurses and midwives regarding how to develop focused and well-structured research questions. This was undertaken using in-service education sessions that were conducted each clinical area; the preferred method of the organisation. The intention was to administer two rounds of questionnaires although the low response rate across a large number of specialty areas in Round One precluded this. However as shown in Table 1, due to the majority of research topics identified as being specific to Learning and Organisational Deyelopment, representatives from this department were asked to rank their importance using a five point Likert-type scale in a Round Two questionnaire. Prior to distributing Round One questionnaires, the methodology was fully explained and nurses and midwives were given the opportunity to ask questions. Study information sheets and questionnaires were distributed by hand to potential participants in each area by the researchers. Questionnaires were anonymous and consent was implied by return of completed questionnaires within the three week deadline.

\section{Round one}

Four hundred and eighty potential expert panel members were identified from eight areas: hospice, medical and surgical wards, midwifery, day procedure unit, emergency, intensive care, specialist nursing services (e.g. stoma, breast care) and operating theatres and recovery. For the purposes of this study, all nurses and midwives were considered experts in their own profession and specialty and invited to participate in the study. Overall, $86(19.2 \%)$ nurses and midwives agreed to participate. 
NURSING AND MIDWIFERY RESEARCH AGENDA: A MODIFIED DELPHI STUDY

\section{Round two}

Fifteen potential expert panel members were identified from the department of learning and development. Of these $10(66.6 \%)$ expert panel members participated from varied areas of practice.

\section{Survey}

\section{Round one}

Round one of the Delphi asked members of the expert panel to respond to the following broad question: 'Please list up to five important questions or problems related to the nursing care and family care of patients you believe should be researched.'

\section{Round two (Learning and Organisational Development)}

The Round Two questionnaire was developed using the Learning and Organisational Development topics identified in Round One. Participants were asked to rank how important each topic was using a five point Likert-type scale. As ten research topics were specific to Learning and Organisational Development in Round One of the Delphi, within Round Two, members of this expert panel (department nursing staff) were asked to rank the importance of each identified topic using a five point Likert-type scale. In the scale, $1=$ unimportant; 2 = of little importance; 3 = moderately important; 4 = important; $5=$ very important.

\section{Ethical considerations}

Ethical approval was obtained from the Human Research Ethics Committee of both the study hospital and it's affiliated university. In accordance with section 2.3.6 of the National Statement on Ethical Conduct in Human Research (National Health and Medical Research Council, 2013), the return of completed questionnaires confirmed consent to participate as the study was considered 'low-risk' and participant responses were quasi-anonymous.

Confidentiality was ensured as no name related data was collected and only group data was presented. Each potential participant received a participation information sheet detailing the 
NURSING AND MIDWIFERY RESEARCH AGENDA: A MODIFIED DELPHI STUDY

study purpose and procedures, an assurance of quasi-anonymity and use of information.

Participants indicated consent to participate by returning completed questionnaires. No name related information was requested, therefore responses were completely non identifiable.

\section{Data analysis}

Descriptive statistics were used to describe the sample according to demographic and practice experience (e.g. age, years of nursing experience), as well as to compute frequencies and proportions for each research topic. Content analysis was used to analyse the Round One survey data. Research topics were transcribed by a research assistant to ensure independence of data. The researchers then coded the data independently using manifest followed by latent coding techniques (Graneheim \& Lundman 2004; Hsieh \& Shannon, 2005 ). Researchers then compared notes and any differences in coding were then reconciled. Researchers compared coded data, discussed each topic and assigned it to a category. If required topics were rewritten to reflect as closely as possible the problem as originally submitted. A process of reduction was then undertaken to condense similar topics into one research heading. Research topics were then assigned to the specialty setting within which nurses and midwives practiced. When a topic was considered more suitable for 'clinical audit' a literature review was undertaken to confirm whether an existing evidence base already existed. A number of topics were considered unsuitable' for inclusion in any category as they fell outside the boundaries of nursing and midwifery practice. Following consensus within the research team, all topics were then assigned to one of the following categories: research; established evidence base; clinical audit; or unsuitable (Table 1).

There is variation in the statistics used to report Delphi results (Keeney, Hasson \& McKenna, 2011) with some debate published in the Delphi literature. While the median is commonly used in Delphi research (Avery et al., 2005; Vogel et al. 2009; Becker et al., 2009), the mean is also advocated by Delphi researchers (Drennan et al., 2007; Efstathiou et 
NURSING AND MIDWIFERY RESEARCH AGENDA: A MODIFIED DELPHI STUDY

al., 2008; Ferguson et al. 2008). As there is merit in viewing both the mean and median, we have provided both in Table 5 for clarity. Research topics from the Round Two questionnaire were therefore computed according to means, standard deviations, medians and IQR. As there is merit in viewing both the mean and median, we have provided both in Table 5 for clarity. Research topics from the Round Two questionnaire were therefore computed according to means, standard deviations, medians and IQR.

This study was based on one question which was deliberately broad and consistent with the modified Delphi technique. The nature of the research priorities was not specified, leaving expert panel members the opportunity to cover a wide range of issues. To reduce individual biases, the researchers collectively analysed all responses and only allocated each response once consensus was achieved. This helped to ensure that the analysis accurately reflected the tabled data.

\section{Results}

\section{Demographic characteristics Round One (Table 2)}

Questionnaires were distributed to 448 eligible nurses and midwives with a $19.2 \%(n=86)$ response rate. The majority of respondents were female and aged between 40 and 59 years, consistent with a 2008 nursing workforce profile published by the Western Australian Department of Health. Respondents had a mean of 21.6 years of nursing or midwifery experience and 9.2 years' experience in their current area of specialty. A large proportion of participants were clinical nurses/midwives $(n=25,31.6 \%)$, registered nurses/midwives $(n=21$, $26.6 \%)$ or senior registered nurses $(n=17,21.5 \%)$. The majority of respondents worked in surgical areas $(n=21$, 
NURSING AND MIDWIFERY RESEARCH AGENDA: A MODIFIED DELPHI STUDY

$28.0 \%)$, hospice $(n=13,17.3 \%)$ or medical areas $(n=12,16.0 \%)$ and were employed on a permanent part-time basis $(\mathrm{n}=48,62.3 \%)$.

\section{Topics identified in round one (Table 3)}

Two hundred and fifty seven topics were initially identified. A number of topics were similar and through a process of reduction were condensed to 181 topics. Topics were written as closely as possible to the problems originally submitted by nurses. Each topic was then discussed by the research group and following content analysis were assigned to one of the following seven specialty categories: palliative care $(n=14)$; midwifery $(n=17)$; intensive/coronary care $(n=9)$; emergency $(n=5)$; workforce $(n=18)$; clinical practice $(n=53)$; continuum of care $(n=16)$; documentation $(n=3)$;

professional practice $(n=11)$; communication $(n=12)$; and learning and development $(n=23)$.

A further process of reduction was undertaken to determine whether topics were more suitable for clinical audit; an evidence base already existed for topics; evidence-based policies or guidelines were currently in place or topics fell outside the scope of nursing or midwifery practice. Consequently topics were allocated to one of the following four categories: clinical audit ( $n=47)$; existing evidence base $(n=40)$; research $(n=23)$; or other $(n=71)$. Of the 23 research topics, 10 focused on learning and development, five focused on workforce and the remaining eight topics were spread across the remaining specialty areas. It was not considered appropriate to conduct a Round Two survey to gain consensus of research topics given the low numbers of topics that were spread across seven specialty areas. The area of Learning and Organisational Development was the exception. As 10 topics had been identified in this specialty area the decision was made to conduct a Round Two Delphi survey with nurses and midwives employed in Learning and Organisational Development. 
NURSING AND MIDWIFERY RESEARCH AGENDA: A MODIFIED DELPHI STUDY

\section{Demographic characteristics Round Two (Table 4)}

Questionnaires were distributed to 15 eligible Learning and Organisation Development nurses and midwives with a $66.6 \%(n=10)$ response rate. The majority of respondents were female $(n=7,87.5 \%)$ and aged between 40 and 59 years $4(50.0 \%)$. Respondents had a mean of 18.2 (sd 7.7) years of nursing or midwifery experience and 6.1 (sd 4.4) years' experience in professional development. A large proportion of participants held either a graduate certificate or graduate diploma $(n=6,75.0 \%)$.

\section{Ranking of Learning and Development Topics round two (Table 5)}

The results of the Round Two ranking of the ten topics identified by Learning and Organisational Development are presented in Table 5. The highest ranked topics were:

1. Does simulated learning assist skill development?

2. Do graduate enrolled nurses require a longer support period in their first year compared with graduate registered nurses in order to successfully transition into the workplace?

3. A comparison between nursing outcomes from the 12 month Technical and Further Education diploma in nursing versus the traditional 18 month Enrolled Nurse diploma in nursing.

\section{Discussion}

While the response rate was low, one of the strengths of the study was the varied experience levels of participants and balanced representation of nurses or midwives working across all clinical areas within the study setting. This provided a variety of clinical practice perspectives to the study. 
NURSING AND MIDWIFERY RESEARCH AGENDA: A MODIFIED DELPHI STUDY

This study showed two striking findings. Although 23 research topics were identified across several clinical areas, the most prominent categories identified were those concerning workforce and learning and organisational development. These categories reflect congruence with the current focus on the key areas of workforce and learning and organisational development in both the study setting and its national parent organisation, one of Australia's leading private healthcare groups. Findings also support two issues of primary concern to the disciplines of nursing and midwifery both in Australia and internationally. These issues relate to workforce and training, and are largely influenced by ageing of the existing nursing workforce globally (Collins-McNeill, Sharpe \& Benbow, 2012), poor retention rates within the profession across many countries (Buchan and Aitkin, 2008; Mbemba, Gagnon, Pare \& Cote, 2013; Schmiededknect, Perera, Schell, Jere, Geoffroy \& Rankin, 2015) and a failure to graduate sufficient numbers of nurses to replace those who retire (Australian Institute of Health and Welfare 2011; Smith and Pilling, 2008; Buchan and Aiken, 2008).

In response to predictions that current nursing workforce arrangements are not sustainable in the longer term major workforce re-design must take place in order to ensure the demand for health service delivery is met. Accordingly many international and Australian healthcare settings have changed their skill mix in order to meet the increasing demand for nurses and maintain access to healthcare services (Royal College of Nursing, 2010; Graham \& Duffield, 2010; Health Information and Quality Authority, 2012).

Our findings likely reflect the impact of changes in workforce sustainability options that had occurred in the study setting when a new nursing model of care was adopted in 2006. At this time, the team nursing model was implemented to replace the previously used patient allocation model. Further workforce sustainability strategies were implemented in 2008 with 
NURSING AND MIDWIFERY RESEARCH AGENDA: A MODIFIED DELPHI STUDY

an agreement to work towards a 70\% registered nurse, $30 \%$ enrolled nurse and 'other' skill including nursing substitute positions such as assistants in nursing. A lack of understanding on the part of nurses and midwives regarding the difference between research and clinical audit was also identified. Many topics identified by nurses and midwives as suitable for research were classified by the researchers as either audit topics or a good evidence base (e.g. systematic reviews) already existed to support the particular area of practice. This finding is consistent with those from similar recent studies conducted in Western Australia,Wilson et al., 2012; Wynaden et al., 2014) and internationally (Squires, Hutchinson, Bostrom, O’Rourke, Cobban \& Estabrooks, 2011). Although there is much rhetoric and pressure for caregivers to use empirical evidence to inform practice, a number of challenges are known to influence utilisation and uptake of research including: time constraints for sourcing, reviewing and access to evidence; infrastructure support to facilitate interpretation of research including statistics, and implementation of evidence (Atkinson Smith, 2011; Fitzsimmons \& Cooper, 2012). Despite the increasing amount of empirical evidence to support nursing and midwifery practice there is still reluctance by nurses and midwives to apply findings to practice (Corchon 2010; Kocaman et al., 2010. Fitzsimmons \& Cooper, 2012). There is an urgent need for innovative strategies such as transformational leadership that will encourage professional growth amongst nurses and facilitate the translation of research into practice (Atkinson Smith, 2011; Fitzsimmons \& Cooper, 2012). The study setting has made a commitment towards raising the profile of nursing and midwifery led collaborative research and promoting a positive culture of evidence based practice. Three topics identified from this Delphi study have been developed into research studies which are currently in progress. 
NURSING AND MIDWIFERY RESEARCH AGENDA: A MODIFIED DELPHI STUDY

\section{Limitations}

The study findings reflect the view of nurses and midwives who were employed in a large tertiary private hospital in Western Australia. Specifically, the results reflect Learning and Organisational Development research priorities in one hospital in Australia. While consistent with response rates for similar studies, the small sample size was also a limiting factor. It is important to note the recommendations from this Delphi study are not applicable to nursing and midwifery in general, but specifically to Learning and Organisational Development research priorities in one hospital in Australia. Despite this limitation compilation of the expert opinions from this group of nurses and midwives employed at this hospital will provide the foundation for the development of priorities for the Centre for Nursing and Midwifery Research at the study setting.

Recruitment and retention of members expert panels can be difficult within the Delphi technique (Keeney, Hasson \& McKenna., 2011) and the present study was no exception as evidenced by the low response rate across some specialties in Round one. While the Delphi technique is not prescriptive concerning the number of experts within each panel, recruitment and retention difficulties may be regarded as a common limitation to Delphi studies. In this study, the low response rate could be due to a lack of motivation due to the demands of caregiving in a busy tertiary setting where managing the complexity of high patient acuity and reduced nursing and midwifery hours is challenging. The inexperience of nurses and midwives as actiye participants in research could also have been a contributing factor.

\section{Conclusion}

The launch of the Centre for Nursing and Midwifery Research is an exciting initiative for the study setting as well as the broader national organisation. This exercise in developing 
NURSING AND MIDWIFERY RESEARCH AGENDA: A MODIFIED DELPHI STUDY research priorities has provided an outline to ensure the research conducted by the Centre is

relevant and supported by caregivers. This exploratory study has enabled nurses and midwives to identify areas of research importance in their clinical area, particularly in the area of Learning and Organisational Development. Including nurses and midwives in the identification of research topics will potentially encourage caregivers to act as change moderators in the quest to raise the awareness and profile of research in the organisation. To address the perceived lack of understanding regarding the characteristics of research and quality improvement, education activities will be presented to all nursing and midwifery caregivers with a focus on quality initiatives and how to conduct high quality clinical audits. These activities will complement research workshops currently conducted in the organisation. The authors acknowledge the enthusiasm and ownership on the part of nurses and midwives who participated and hope this will encourage them and other colleagues to support ongoing research efforts.

\section{Acknowledgements}

We acknowledge all participants for their involvement and Sarah Harris for her administrative support.

Disclosure statement No competing interests declared. 
NURSING AND MIDWIFERY RESEARCH AGENDA: A MODIFIED DELPHI STUDY

\section{References}

Atkinson Smith, M. (2011). Are you a transformational leader? Nursing Management, 42(9), 44-50. doi: 10.1097/01.NUMA.0000403279.04379.6a

Australian College of Nursing. Nursing Research Position Statement. Canberra: 2013.

Australian Institute of Health and Welfare. (2011). Nursing and Midwifery Labour Force 2009. Vol. Bulletin no. 90. Canberra: AIHW.

Avery, A.J., Savelyich, B.S.P., Sheikh, A., Cantrill, J., Morris, C.J., Fernandon, B. et al. (2005). Identifying and establishing consensus on the most important safety features of GP computer systems: e-Delphi study. Informatics in Primary Care, 13(1), 3-11.

Balakas, K. \& Sparks, L. (2010). Teaching Research and Evidence-Based Practice Using a Service Learning Approach. Journal of Nursing Education, 49(12), 691-695. doi: $10.3928 / 01484834-20100831-07$

Becker, G.E. (2009). Do we agree? Using a Delphi technique to develop consensus on skills of hand expression. Journal of Human Lactation, 25(2), 220-225. doi: $10.1177 / 0890334409333679$

Blackwood, B., Albarran, J.W \&Latour, J.M. (2011). Research priorities of adult intensive care nurses in 20 European countries: a Delphi study. Journal of Advanced Nursing, 67(3), 550-562. doi: 10.1111/j.1365-2648.2010.05512.x

Brenner, M., Hillard, C., Regan, G., Coughlan, B., Hayden, S., Drennan, J. \& Kelleher, D. (2014). Journal of Pediatric Nursing, 29(4), 301-308. doi: http://dx.doi.org/10.1016/j.pedn.2014.01.003

Buchan, J. \& Aiken, L. (2008) Solving nursing shortages: a common priority. Journal of Clinical Nursing, 17(24), 3262-3268. doi: 10.1111/j.1365-2702.2008.02636.x 
NURSING AND MIDWIFERY RESEARCH AGENDA: A MODIFIED DELPHI STUDY

Collins-McNeil, J. Sharpe, D. \& Benbow, D. (2012). Aging workforce: Retaining valuable nurses. Nursing Management, 43(3), 50-51. doi:

10.1097/01.NUMA.0000412228.68794.fa

Corchon, S. (2010). Commentary on Kocaman G, Seren S, Lash A. A, Kurt S, Bengu N \& Yurumezoglu H. A. Barriers to research usage by staff nurses in a university hospital. Journal of Clinical Nursing, 19(13-14), 2076-2078. doi:10.1111/j.13652702.2010.03207.x

Department of Health and Ageing. (2013). Strategic Review of Health and Medical Research: Final Report. Canberra: Department of Health and Ageing.

de Vries, K., Walton, J., Nelson, K. \& Knox, R. (2015). An examination of the research priorities for a hospice service in New Zealand: A Delphistudy. Palliative and Supportive Care, FirstView:1-9. doi:10.1017/S1478951515000838

Drennan, J., Meehan, T., Kemple, M., Johnson, M. Treacy, M. \& Butler, M. (2007). Nursing research priorities for Ireland. Nursing Scholarship, 39(4), 298-305.

Efstathiou N., Coll A.M., Ameen J.\& Daly W. (2011) Do Greek healthcare users and healthcare providers share cancer care priorities? Analysing the results from two Delphi studies. European Journal of Cancer Care, 20(2), 179-186. doi:10.1111/ j.1365-2354.2009.01176.x

Ferguson, F.C., Brownlee \& Webster, V. (2008). A Delphi study investigating consensus among expert physiotherapists in relation to the management of low back pain. Musculoskeletal Care, 6(4), 197-210. doi: 10.1002/msc.126

Fitzsimmons, E. \& Cooper, J. (2012). Embedding a culture if evidence-based practice. Nursing Management, 19(7), 14-19. doi: 10.7748/nm2012.11.19.7.14.c9370 
NURSING AND MIDWIFERY RESEARCH AGENDA: A MODIFIED DELPHI STUDY

Graham, E.M. \& Duffield, C. (2010). An ageing nursing workforce. Australian Health Review, 34, 44-48. doi: http://dx.doi.org/10.1071/AH09684

Graneheim, U.H. \& Lundman, B. (2004). Qualitative content analysis in nursing research: concepts, procedures and measures to achieve trustworthiness. Nurse Education Today, 24,(2), 105-112. doi:10.1016/j.nedt.2003.10.001

Green, A., Gance, B., Smith, A., Ely, E \& McDowell, B. (2014). Journal of Pediatric Nursing, 29(5), 401-409. doi: 1053/j.akkd.2015.02.341

Grundy, M. \& Ghazi, F. (2009). Research priorities in haemato-oncology nursing: Results of a literature review and a Delphi study. European Journal of Oncology Nursing, 13 (4), 235-249. doi:10.1016/j.ejon.2009.03.002

Health Information and Quality Authority (2012). NationalStandards for Better Safer Healthcare. Health Information and Quality Authority, Dublin, Ireland

Hsieh, H.-F. \& Shannon, S.E. (2005). Three approaches to qualitative content analysis.

Qualitative Health Research, 15(9), 1277-1288. doi: 10.1177/1049732305276687

Jordan, K., Slavin, V. \& Fenwick, J.(2013). Research priorities of midwives: a Delphi study. Practical Midwifery, 16(3), 26-28.

Keeney, S., Hasson, F. \& McKenna, H. (2011). The Delphi Technique in Nursing and Health Research, Wiley-Blackwell, United Kingdom.

Kocaman, G., Seren, S. \& Lash, A.A. (2010). Barriers to research utilisation by staff nurses in a university hospital. Journal of Clinical Nursing, 19(13-14), 1908-1918.

Mbemba, G., Gagnon, M.P., Pare, G. \& Cote, J. (2013). Interventions for supporting nurse retention in rural and remote areas: an umbrella review. Human Resources for Health, 11, 44. doi: 10.1186/1478-4491-11:44 
NURSING AND MIDWIFERY RESEARCH AGENDA: A MODIFIED DELPHI STUDY

Melnyk, B.M., Fineout-Overholt, E., Gallagher-Ford, L \& Kaplan L. (2012). The state of evidence-based practice in US nurses: critical implications for nurse leaders and educators. Journal of Nursing Administration, 42(9): 410-417. Doi:

http://dx.doi.org/10.1097/NNA.0b013e3182664e0a

National Health and Medical Research Council. (2013). Australian code for the care and use of animals for scientific purposes, 8th edition. Canberra: National Health and Medical Research Council.

Nursing and Midwifery Board of Australia. (2015). Professional Codes and Guidelines. In Framework for Assessing standards for practice for registered nurses, enrolled nurses and midwives. Principles for Assessment: Principle of Evidence Based Assessment. Retrieved on 28 October 2015 from http://www.nursingmidwiferyboard.gov.au/Codes-Guidelines-

Statements/Frameworks/Framework-for-assessing-national-competencystandards.aspx.

Oberst, M. (1978). Priorities in cancer nursing research. Cancer Nursing, 1(4), 281-290.

Ramelet, A-S. \& Gill, F.(2012). A Delphi Study on National PICU nursing research priorities in Australia and New Zealand. Australian Critical Care, 25(1), 41-57. doi: http://dx.doi.org/10.1016/j.aucc.2011.08.003

Royal College of Nursing (2010). Guidance on Safe Nurse Staffing Levels in the UK. Royal College of Nursing, London UK.

Schmiedeknecht, K., Perera, M., Schell, E., Jere, J., Geoffroy, E. \& Rankin, S. (2015).

Predictors of workforce retention among Malawian nurse graduates of a scholarship program: a mixed methods study. Global Health Science Practitioner, 3(1) 85-96. doi: 10.9745/GHSP-D-14-00170 
Sheikh, K. George, A. \& Gibson, L. (2014). Health Research Policy and Systems, 12(19), 18. doi:10.1186/1478-4505-12-19

Smith, R. \& Pilling, S. (2008). Supporting the transition from student to professional - a case study in allied health. Australian Health Review, 32(1), 134-138. http://dx.doi.org/10.1071/AH080134

Squires, J.E., Hutchinson, A.M., Bostrom, A.M., O’Rourke, H.M., Cobban, S.J. \& Estabrooks, C.A. (2011). To what extent do nurses use research in clinical practice? A systematic review Implementation Science 6:21. doi: 10.1186/1748-5908-6-21

Tong, A., Crowe, S., Chando, S., Cass, A., Chadbane S.J., Chapman, J.R et al. (2015). American Journal of Kidney Diseases, 66(2), 212-222. doi: 10.1053/j.ajkd.2015.02.341

Tume, L., van den Hoogen, A., Wielenga, J. \& Latour, J.M. (2012). An Electronic Delphi Study to Establish Pediatric Intensive Care Nursing Research Priorities in Twenty European Countries. Pediatric Critical Care Medicine, 28(3), 137-142. doi: 10.1097/NND.0b013e3182551543

Vogel, I., Brug, J., Van der Ploeg, C.P.B., \& Raat, H. (2009). Prevention of adolescents' music-induced hearing loss due to discotheque attendance: a Delphi study. Health Education Research, 24(6), 1043-1050. doi: 10.1093/her/cyp031

Wielenga, J., Tume, L.N., Latour, J.M. \& van den Hoogen, A. (2014). European neonatal intensive care nursing research prioritieis: an e-Delphi study. (2014). Pediatric Critical Care, 15(5), e206-e213. doi: doi: 10.1097/PCC.0000000000000109

Wilkes, L. (2015). Using the Delphi technique in nursing research. Nursing Standard. 29(39), 43-49. doi: http://dx.doi.org/10.7748/ns.29.39.43.e8804 
Wilson, S., Y. L. Hauck, A. P. Bremner, \& J. Finn. (2012). Quality nursing care in Australian paediatric hospitals: A Delphi approach to identifying indicators. Journal of Clinical Nursing, 21 (11-12): 1594-1605. doi: 10.1111/j.1365-2702.2011.04004.x

Wynaden, D, Heslop. K. Omari, O.A., Nelson, D, Osmond, B, Taylor, M. \& Gee, T. (2014). Identifying mental health nursing research priorities: A Delphi study. Contemporary Nurse, 47(1-2), 16-26. doi: 10.1080/10376178.2014.11081902 
NURSING AND MIDWIFERY RESEARCH AGENDA: A MODIFIED DELPHI STUDY

Table 1 Allocation of topics according to categories across the domains of clinical audit, existing evidence base, research and other $(\mathrm{N}=181)$

\begin{tabular}{|c|c|c|c|c|}
\hline Category & $\begin{array}{l}\text { Clinical } \\
\text { audit } \\
n(\%)\end{array}$ & $\begin{array}{c}\text { Existing } \\
\text { evidence base } \\
n(\%)\end{array}$ & $\begin{array}{l}\text { Research } \\
n(\%)\end{array}$ & $\begin{array}{l}\text { Other } \\
n(\%)\end{array}$ \\
\hline Palliative care & $3(6.4)$ & $1(2.5)$ & $2(8.7)$ & $8(11.3)$ \\
\hline Midwifery & $6(12.8)$ & $4(10.0)$ & $1(4.3)$ & \\
\hline $\mathrm{ICU} / \mathrm{CCU}$ & $2(4.3)$ & $3(7.5)$ & $1(4.3)$ & \\
\hline Emergency & $2(4.3)$ & $0(0.0)$ & $1(4.3)$ & ) \\
\hline Workforce & $1(2.1)$ & $8(20.0)$ & & $4(5.7)$ \\
\hline Clinical practice & $21(44.6)$ & $13(32.5)$ & & $17(23.7)$ \\
\hline Continuum of care & $6(12.7)$ & $5(12.5)$ & $0(0.0)$ & $5(7.0)$ \\
\hline Documentation & $2(4.3)$ & & $0(0.0)$ & $1(1.4)$ \\
\hline Professional practice & $1(2.1)$ & & $1(4.3)$ & $5(7.0)$ \\
\hline Communication & $2(4.3)$ & $1(2.5)$ & $0(0.0)$ & $9(12.7)$ \\
\hline $\begin{array}{l}\text { Learning and } \\
\text { development }\end{array}$ & & $1(2.5)$ & $10(43.6)$ & $11(15.8)$ \\
\hline
\end{tabular}


Table 2 Demographic Characteristics of Expert Panels Members for Round One $(n=86)$.

\begin{tabular}{|c|c|}
\hline Characteristic & $\mathrm{n}(\%)$ \\
\hline \multicolumn{2}{|l|}{ Age* } \\
\hline 20-29 years & $8(10.3)$ \\
\hline 30-39 years & $12(15.4)$ \\
\hline 40-49 years & $28(35.9)$ \\
\hline 50-59 years & $26(33.3)$ \\
\hline $60-69$ years & $4(5.1)$ \\
\hline \multicolumn{2}{|l|}{ Gender* } \\
\hline \multicolumn{2}{|l|}{ Female } \\
\hline \multicolumn{2}{|l|}{ Male } \\
\hline \multicolumn{2}{|l|}{ Area of employment* } \\
\hline \multicolumn{2}{|l|}{ Surgical areas } \\
\hline Hospice & $13(17.3)$ \\
\hline Medical areas & $12(16.0)$ \\
\hline Obstetrics & $11(14.7)$ \\
\hline DPU & $9(12.0)$ \\
\hline $\mathrm{ED} / \mathrm{ICU}$ & $5(6.7)$ \\
\hline Specialist nursing services & $2(2.7)$ \\
\hline Operating theatre/recovery & $1(1.3)$ \\
\hline Other & $1(1.3)$ \\
\hline \multicolumn{2}{|l|}{ Job classification* } \\
\hline Clinical Nurse/Midwife & $25(31.6)$ \\
\hline Registered Nurse/I & $21(26.6)$ \\
\hline Senior Registered & $17(21.5)$ \\
\hline Nursing admin & $9(11.4)$ \\
\hline Enrolled $\mathrm{Nu}$ & $5(6.3)$ \\
\hline Other & $2(2.5)$ \\
\hline \multicolumn{2}{|l|}{ Employment* } \\
\hline Part-time-permanent & $48(62.3)$ \\
\hline Full-time - permanent & $28(36.4)$ \\
\hline Casual Pool & $1(1.3)$ \\
\hline
\end{tabular}

* missing data 
Table 3 Research topics according to clinical area

\begin{tabular}{ll}
\hline Clinical area & Research Topic \\
\hline Learning and & Does simulated learning assist skill development? \\
development & $\begin{array}{l}\text { Do graduate enrolled nurses require a longer support period in their } 1^{\text {st }} \text { year } \\
\text { compared with graduate RNs in order to successfully transition into the }\end{array}$ \\
& workplace? \\
& Identify the most effective methods of clinical supervision. \\
& Does an onsite clinical school enhance transition to practice for enrolled \\
& nurses? \\
& Do graduate qualifications enhance nurses' clinical practice at the bedside? \\
& Does our current model of care meet the support of our graduate nurses? \\
& Evaluation of a graduate mentorship programme. \\
& The effect of using $3^{\text {rd }}$ year undergraduates to mentor $1^{\text {st }}$ year undergraduate \\
& registered nurses. \\
& Cultural diversity and the impact on transition to practice: the effect on \\
& confidence and competence of graduates. \\
& The new 12-month compact Enrolled Nursing Course versus the traditional \\
& 18-month Enrolled Nursing Course: a pilot comparative study.
\end{tabular}

Workforce What are the characteristics of the team nursing model at SJGMH? Identify ways of improving the current team nursing model to better facilitate managing the increasing junior workforce.

Does the team nursing model of care reduce the incidence of adverse events?

What is the impact of the 70/30 registered nurse/enrolled nurse mix on patient experience, satisfaction and health outcomes?

What is the effect of team nursing on communication between nursing and midwifery staff?

Clinical Explore the effectiveness and merits of different modes of cryotherapy in practice orthopaedic patients.

Identify patients at risk of wound infection and dehiscence and

implementation of preventative strategies to reduce the risk (e.g. nutritional

supplements, mechanisms to facilitate earlier detection of wound infection and breakdown).

How does diagnosis-related depression impact ongoing patient care?

Palliative care Explore staff education needs and perceptions in provision of palliative care. Does clinical supervision effectively support palliative care nurses?

ICU/CCU Explore ICU/CCU staff perceptions regarding the introduction of enrolled nurses to these clinical areas.

Professional Explore and describe the model of succession planning for the nursing and practice midwifery workforce.

Midwifery $\quad$ Explore more accurate methods of measuring infant length. 
Table 4 Demographic Characteristics of Expert Panels Members for Round Two $(n=10)$

Characteristic

\begin{tabular}{cc}
\hline Age* $^{*}$ & $\mathrm{n}(\%)$ \\
$20-29$ years & $2(25.0)$ \\
$30-39$ years & $1(12.5)$ \\
$40-49$ years & $4(50.0)$ \\
$50-59$ years & $1(12.5)$ \\
Gender* & $\mathrm{n}(\%)$ \\
Female & $7,(87.5)$ \\
Male & $1(12.5)$ \\
Area of employment* & $\mathrm{n}(\%)$ \\
Surgical areas & $2(25.0)$ \\
Operating theatre/PACU & $2(25.0)$ \\
DPU & $1(12.5)$ \\
ED/ICU & $1(12.5)$ \\
Other & $2(25.0)$ \\
Job classification* & $\mathrm{m}(\mathrm{sd})$ \\
Nursing experience (years) & $18.2(7.7)$ \\
Professional development experience (years) & $6.1(4.4)$ \\
Learning and organisational development experience & $3.6(3.21)$ \\
Postgraduate qualifications* & $\mathrm{n}(\%)$ \\
Certificate & $2(25.0)$ \\
Graduate certificate & $3(37.5)$ \\
Graduate diploma & $3(37.5)$ \\
\hline
\end{tabular}

*Missing data 
Table 5

Ranking of the ten topics identified by Learning and Organisational Development

\begin{tabular}{|c|c|c|c|c|c|}
\hline Topic & Mean & $S D$ & $M d$ & IQR & Rank \\
\hline $\begin{array}{l}\text { Does simulated learning assist skill } \\
\text { development? }\end{array}$ & 4.6 & 0.70 & 5.0 & $4.00-5.00$ & 1 \\
\hline $\begin{array}{l}\text { Do graduate enrolled nurses (ENs) } \\
\text { require a longer support period in } \\
\text { their first year compared with } \\
\text { graduate registered nurses in order } \\
\text { to successfully transition into the } \\
\text { workplace? }\end{array}$ & 4.2 & 1.03 & 4.5 & $3.00-5.00$ & 2 \\
\hline $\begin{array}{l}\text { A comparison between nursing } \\
\text { outcomes from the } 12 \text { month } \\
\text { Technical and Further Education } \\
\text { (TAFE) diploma in nursing versus } \\
\text { the traditional } 18 \text { month EN } \\
\text { diploma in nursing }\end{array}$ & 4.1 & 1.37 & 5.0 & & 3 \\
\hline $\begin{array}{l}\text { Does our current model of care } \\
\text { adequately support our graduate } \\
\text { nurses? }\end{array}$ & 4.0 & & & $3.00-4.5$ & 4 \\
\hline $\begin{array}{l}\text { The effect of culture on the } \\
\text { confidence and competence of } \\
\text { graduates }\end{array}$ & & & 3.5 & $1.0-4.25$ & 5 \\
\hline $\begin{array}{l}\text { Identify effective methods of } \\
\text { clinical supervision }\end{array}$ & & 1.43 & 3.5 & $3.75-5.00$ & 5 \\
\hline $\begin{array}{l}\text { Evaluation of our graduate } \\
\text { mentorship programme }\end{array}$ & 3.4 & 1.35 & 3.0 & $2.75-5.00$ & 6 \\
\hline $\begin{array}{l}\text { The impact of using third year } \\
\text { undergraduates mentoring first } \\
\text { year undergraduates }\end{array}$ & 3.3 & 1.42 & 3.0 & $2.00-5.00$ & 7 \\
\hline $\begin{array}{l}\text { Does an onsite clinical school } \\
\text { enhance transition to practice for } \\
\text { ENs? }\end{array}$ & 3.0 & 1.49 & 3.0 & $2.75-5.00$ & 8 \\
\hline $\begin{array}{l}\text { Do post graduate qualifications } \\
\text { enhance nurses' clinical practice at } \\
\text { the bedside? }\end{array}$ & 3.0 & 1.63 & 3.5 & $3.00-5.00$ & 9 \\
\hline
\end{tabular}

